\title{
Pitfall trapping for surveying trapdoor spiders: the importance of timing, conditions and effort
}

Ian Engelbrecht: Directorate of Nature Conservation, Gauteng Department of Agriculture and Rural Development, 73 Market Street, Johannesburg, South Africa; Department of Zoology and Entomology, University of Pretoria, Pretoria, South Africa. E-mail: ian.engelbrecht@gauteng.gov.za

\begin{abstract}
Trapdoor spiders are challenging to sample using active searching methods because of their cryptic burrowing behavior. This poses problems for ecological studies and for gathering the data needed for conservation assessments. Pitfall trapping provides an alternative method that targets adult males as they wander from their burrows in search of females. Using pitfall trapping requires considerations of the timing of sampling within the year, the effects of environmental conditions on spider activity, and sampling effort required for a high probability of detecting species that are present at a sample site. To investigate these factors, pitfall-trapping surveys were conducted at several localities in Gauteng Province, South Africa. The results showed that trapdoor spider activity occurs in all seasons. Each species has a discrete period of activity ranging from a few weeks to several months in duration. Some species are active at different times of the year at different localities. Statistical analysis showed soil moisture as the only significant predictor of activity from amongst seven environmental variables, and the survey results indicate that trapdoor spiders are active under wet conditions following rainfall. Between two and seven nights of trapping are required for a high probability of detecting all species present and active at a site, using the trap design employed for this study with ten trap arrays per site. Trapping must be repeated at regular intervals throughout the year in order to obtain a near complete inventory of the species assemblage. The number of species collected ranged from two to eight per site, with most sites having six or eight species. Pitfall trapping yielded 1.23.0 times the number of species obtained by active searching at sites where both methods were employed. Guidelines for planning pitfall-trapping surveys of trapdoor spiders are presented and future research directions are discussed.
\end{abstract}

Keywords: Conservation, detection probability, Mygalomorphae, phenology, sampling

Sampling rare and elusive species is inherently challenging (Thompson 2004), which is problematic because these species are often most in need of conservation attention. Systematic conservation planning and biogeographical studies require sound species distribution data (Margules \& Pressey 2000; Whittaker et al. 2005), and gathering such data requires effective sampling methods. Sampling rare and elusive species can require specialized or advanced field methods and sophisticated statistical tools. Small sample sizes are sometimes characteristic of such species, and low detection probabilities confound analysis (Lancia et al. 1994; Cunningham \& Lindenmayer 2005; MacKenzie et al. 2005). Researchers should invest some effort in developing sampling methods that provide relatively high probabilities of detecting a species at a sample site if it occurs there, before undertaking further research for conservation purposes (McDonald 2004).

Trapdoor spiders are long-lived, slow reproducing, burrowing spiders with several species of conservation concern in different parts of the world (Clarke \& Spier-Ashcroft 2003; Bond et al. 2006; Cooper et al. 2011; Engelbrecht \& Prendini 2012). Many species construct burrows in the soil, which they cover with a lid that resembles the surrounding substrate. These burrows are often nearly impossible to detect with the naked eye. Increasing recognition of the conservation significance of these spiders and the resulting need for additional research requires effective sampling methods. The challenge is that their cryptic burrowing behavior makes them difficult to sample. Dippenaar-Schoeman (2002) and van Dam \& Roberts (1917) described active searching methods for collecting trapdoor spiders, which include scanning the soil surface by eye, brushing away loose soil or surface debris, or scraping away the top few millimeters of soil with a spade to locate burrows. When burrows are located they are excavated to obtain the occupant. Pitfall trapping is a passive sampling method often employed in studies of ground-living, cursorial arthropods (Uetz \& Unzicker 1976; Southwood \& Henderson 2000; Woodcock 2005). Traps may be placed singly or in arrays or grids and may contain preservative or be used to obtain live specimens. Although juvenile and female trapdoor spiders are largely sedentary and seldom leave their burrows, adult males wander from their burrows in search of females (e.g., Main 1957; Coyle \& Icenogle 1994; Dippenaar-Schoeman et al. 2006), which is when they fall into pitfall traps. This leads to male bias in pitfall trap samples, while active searching predominantly yields females and juveniles.

Trapdoor spiders are often collected in pitfall traps during general surveys of spider assemblages (e.g., Whitmore et al. 2001; Russell-Smith 2002; Warui et al. 2004; Dippenaar et al. 2008; Foord et al. 2008), but using this method to specifically inventory trapdoor spider assemblages requires consideration of timing of sampling and sampling effort. Timing of sampling is important because different species may be active at different times of the year and for varying durations, and activity may be affected by weather and other environmental conditions. Discrete periods of activity, or phenology, of adult male mygalomorphs have been demonstrated for two microstigmatid species occurring syntopically in KwaZulu-Natal, South Africa (Dippenaar-Schoeman et al. 2006); for antrodiaetids in North America (Coyle 1971; Coyle \& Icenogle 1994) and are indicated in some taxonomic articles (e.g., Gallon 2002; Bond \& Opell 2002; Wishart 2006, 2011). Coyle (1971) and Coyle \& Icenogle (1994) noted that male antrodiaetid activity was also associated with rainy periods in North America, and Main (1957) stated that male idiopids wander after the first winter rains in southern Australia. Weather and other environmental conditions such as moon illuminance affect 
activity levels in many insect taxa and in turn influence trapping success (Williams 1940; Austin et al. 1976). To date no detailed studies of the influence of such factors on mygalomorph spiders have been published. Sampling effort is important because it has a significant influence on the probability of detecting a species at a sampling location if the species is present. As sampling effort increases, so the probability of detecting the species present increases. This has obvious implications for biodiversity surveys. The importance of including detection probability in ecological studies and monitoring programs has received significant attention (MacKenzie et al. 2002; Kéry \& Schmidt 2008; GuilleraArroita et al. 2010).

The goals of the study presented here were as follows: 1) to investigate seasonal activity patterns, or phenology, of trapdoor spiders; 2) to assess the effects of weather and other environmental conditions on surface activity of trapdoor spiders; 3) to determine the sampling effort required to detect the species present in an assemblage with relative certainty and 4) to compare the effectiveness of active searching and pitfall trapping for inventorying species assemblages. The term 'trapdoor spider' is often applied loosely to several mygalomorph spider families, although some do not make trapdoors on their retreats. In this article it is used to refer to the families Ctenizidae, Cyrtaucheniidae, and Idiopidae in the South African context.

\section{METHODS}

Phenology and environmental conditions.-An initial survey was conducted at Roodeplaat Dam Nature Reserve $\left(25^{\circ} 37^{\prime} 55^{\prime \prime} \mathrm{S}, 28^{\circ} 21^{\prime} 25^{\prime \prime} \mathrm{E}\right.$; $\left.1235 \mathrm{masl}\right)$, approximately $10 \mathrm{~km}$ NE of Pretoria, Gauteng Province, South Africa. Summers in northern Gauteng Province are warm and wet with temperatures reaching the mid-thirties Celsius during the day and with an average annual rainfall of around $650 \mathrm{~mm}$ (Schultz 1997). Winters are cool and dry with an average of 21 frost days per year (Schultz 1997). The survey was conducted in a homogenous habitat area approximately 15 ha in size on a gentle, NW facing slope; red, sandy clay loam soil and sparse rock cover $(<1 \%)$. The vegetation is tall, open Acacia caffra woodland with bush clumps dominated by Olea europaea subsp. africana, Euclea crispa, Ehretia rigida, Ziziphus mucronata and Protasparagus sauvedens. The herb layer is dominated by the grasses Eragrostis chloromelas and Cymbopogon excavatus, with Aloe greatheadii var. davyana abundant. The reserve has a low abundance of game, and the study site is burned every few years as part of the management regime.

Pitfall trap cross arrays were used for the survey. Each trap array comprised a central trap with four arms of five traps, each radiating at right angles to each other from the central trap. Each individual trap consisted of a $13-\mathrm{cm}$ diameter plant pot submerged in the ground with a 1-liter clear plastic container of the same diameter placed into it, with its rim flush with the soil surface. This design allowed the plastic tub to be removed for inspection during trapping periods without the hole in the ground collapsing. A plastic funnel $4 \mathrm{~cm}$ high and with an aperture of $6 \mathrm{~cm}$ was placed into the rim of the clear plastic container to prevent any captured specimens from climbing out. A mixed experimental design using 16 trap arrays was employed to determine if drift fences and trap density had an effect on the number of specimens captured in a trap array. Eight trap arrays had drift fences installed and eight did not, and eight had individual traps placed $1 \mathrm{~m}$ apart while the other eight had them placed $2 \mathrm{~m}$ apart. Drift fences were made of $150 \mathrm{~mm}$ wide, black polyethylene plastic strips stapled together and held in place between traps with 200-mm nails. The results of the trap design experiment are not reported here. The cross array design allowed for effective use of drift fences without the outer traps shielding the inner traps. The drift fences also made the trap arrays visible from a distance so that they could be located easily and so that animals were less likely to trample them accidentally.

Trapping took place from early spring (19 September 2008) to late autumn (22 May 2009). Traps were opened every Monday afternoon and checked and closed between 06:00 and 07:00 the next morning. This procedure was repeated again on Thursdays, so that the traps were operated for two nights per week. No preservative was used in the traps. All live specimens found in the traps were marked with a small spot of writing correction ink on the posterior part of the thoracic region of the carapace and released in an attempt to determine population size using mark-recapture methods. Dead specimens, either drowned in rainwater that had accumulated overnight or killed by other occupants of the traps, were collected as vouchers for identification. Specimens were identified by comparing them with the original species descriptions and the type specimens of the species described from the Pretoria region, which are predominantly held in the Ditsong National Museum of Natural History (formerly the Transvaal Museum) in Pretoria.

Relationships between activity levels and environmental conditions were investigated for the four species with the largest sample sizes and for all species together. Counts of specimens per species were summed across all traps. For each species zero-counts outside of the period of activity were not included in the analysis. Count data from passive trapping combines the effects of varying population density and activity levels into a single measurement (Williams 1940; Curtis 1980; Southwood \& Henderson 2000). Therefore, studies of one of these factors must control for the other (Briers et al. 2003; Høye \& Forschhammer 2008). Because surface activity was the factor of interest in this study, counts were transformed to presence/absence of the species on each day that the traps were operated, to control for seasonal variation in abundance of wandering males.

Logistic regression was used to analyze the relationship between activity and environmental conditions. Seven variables were included in the analysis. These were averages for temperature, humidity and wind speed; percentage moon illumination; evaporative demand of the atmosphere and relative soil moisture content on each night that the traps were open; and total rainfall over $72 \mathrm{~h}$ before the traps were checked. Hourly temperature, humidity, wind speed and rainfall data were obtained from a weather station situated approximately three kilometers from the sample site and used to calculate nightly averages. Evaporative demand was calculated using a simplified Penman equation (Valiantzas 2006). Soil moisture was not measured, but was estimated for $15-\mathrm{cm}$ soil depth (approximate average depth of spider burrows) using the point soil moisture balance model of 
Table 1.-Localities where pitfall trapping surveys were conducted for trapdoor spiders in Gauteng Province with habitat descriptions and survey dates. Vegetation structural classifications follow Edwards (1983).

\begin{tabular}{|c|c|c|c|c|c|}
\hline Survey site/Coordinates & $\begin{array}{c}\text { Elevation } \\
\text { (masl) }\end{array}$ & $\begin{array}{c}\text { Annual } \\
\text { Rainfall }(\mathrm{mm})\end{array}$ & Habitat & Survey season & $\begin{array}{l}\text { No. of } \\
\text { trap arrays }\end{array}$ \\
\hline $\begin{array}{l}\text { Boekenhoutskloof } \\
25^{\circ} 34^{\prime} 42^{\prime \prime} \mathrm{S} 28^{\circ} 28^{\prime} 58^{\prime \prime} \mathrm{E}\end{array}$ & 1280 & 658 & $\begin{array}{l}\text { Short, moderately closed Faurea } \\
\text { saligna - Terminalia sericea } \\
\text { woodland on soft sand. }\end{array}$ & October 2010-June 2011 & 20 \\
\hline $\begin{array}{l}\text { Onderstepoort Nature } \\
\text { Reserve } 25^{\circ} 36^{\prime} 31^{\prime \prime} \mathrm{S} \\
28^{\circ} 07^{\prime} 07^{\prime \prime} \mathrm{E}\end{array}$ & 1245 & 636 & $\begin{array}{l}\text { Low, moderately closed } \text { Acacia } \\
\text { nilotica woodland on vertic } \\
\text { clay soils. }\end{array}$ & October 2010-June 2011 & 20 \\
\hline $\begin{array}{l}\text { Zwartkoppies } 25^{\circ} 45^{\prime} 21^{\prime \prime} \mathrm{S} \\
28^{\circ} 24^{\prime} 47^{\prime \prime} \mathrm{E}\end{array}$ & 1350 & 681 & $\begin{array}{l}\text { Low, semi-open Acacia karroo } \\
\text { woodland on dolorite derived, } \\
\text { red structured clay soils. }\end{array}$ & October 2010-June 2011 & 20 \\
\hline $\begin{array}{l}\text { Faerie Glen Nature Reserve } \\
25^{\circ} 46^{\prime} 23^{\prime \prime} \mathrm{S} 28^{\circ} 17^{\prime} 35^{\prime \prime} \mathrm{E}\end{array}$ & 1360 & 696 & $\begin{array}{l}\text { Low, open mixed bushland on shale } \\
\text { derived, red loamy clay soils. } \\
\text { Significant weedy herb layer present. }\end{array}$ & October 2011-June 2012 & 10 \\
\hline $\begin{array}{l}\text { Luipaardsvlei } 26^{\circ} 13^{\prime} 33^{\prime \prime} \mathrm{S} \\
27^{\circ} 43^{\prime} 23^{\prime \prime} \mathrm{E}\end{array}$ & 1645 & 667 & $\begin{array}{l}\text { Low, semi-open grassland on red, } \\
\text { sandy loam soil. }\end{array}$ & October 2011-June 2012 & 10 \\
\hline Uitzicht & 1295 & 667 & $\begin{array}{l}\text { Low, semi-open mixed bushland on } \\
\text { shale derived, red loamy clay soils. }\end{array}$ & October 2011-June 2012 & 10 \\
\hline $\begin{array}{l}\text { Holgatfontein } 26^{\circ} 25^{\prime} 21^{\prime \prime} \mathrm{S} \\
\quad 28^{\circ} 34^{\prime} 19^{\prime \prime} \mathrm{E}\end{array}$ & 1600 & 669 & $\begin{array}{l}\text { Short, closed grassland on a mosaic } \\
\text { of sandy and melanic clay soils } \\
\text { in a valley bottom. }\end{array}$ & $\begin{array}{l}\text { October 2011-January } \\
\quad 2012\end{array}$ & 10 \\
\hline $\begin{array}{l}\text { Ezemvelo Nature Reserve } \\
\text { (Lookout) } 25^{\circ} 41^{\prime} 31^{\prime \prime} \mathrm{S} \\
28^{\circ} 56^{\prime} 15^{\prime \prime} \mathrm{E}\end{array}$ & 1370 & 681 & $\begin{array}{l}\text { Short, closed grassland on grey, } \\
\text { gritty sandy loam soils. }\end{array}$ & February to April, 2012 & 10 \\
\hline $\begin{array}{l}\text { Ezemvelo Nature Reserve } \\
\text { (red sand) } 25^{\circ} 42^{\prime} 36^{\prime \prime} \mathrm{S} \\
28^{\circ} 56^{\prime} 28^{\prime \prime} \mathrm{E}\end{array}$ & 1381 & 678 & $\begin{array}{l}\text { Tall, sub-continuous grassland on } \\
\text { soft, red sand. }\end{array}$ & February to April, 2012 & 10 \\
\hline
\end{tabular}

Rodriquez-Iturbe and Porporato (2004:32). Soil and vegetation parameter values needed for the model were obtained from Rodriquez-Iturbe and Porporato (2004), Scholes and Walker (1993) and the Agricultural Research Council's Institute for Soil, Climate and Water. All seven environmental variables were included simultaneously in the analysis, without interactions, to identify any significant predictors of activity.

Sampling effort.-Following the study at Roodeplaat Dam Nature Reserve, pitfall trapping surveys were undertaken at several other localities in Gauteng Province representing a range of habitat types (Table 1, Fig. 1). A trap design similar to that described above was used. Trap arrays of 21 traps each were used, with traps $1 \mathrm{~m}$ apart and with drift fences installed. Traps at each site were operated for one to five days after rainfall events, with sampling events between two weeks to a month apart, from October to the following May. The number of adult males per species was recorded per trap array. Voucher specimens were collected for all species at all sites.

To determine detection probabilities relative to sampling effort, the data were first aggregated to obtain the number of times a species was caught in a trap array (successes) and the total number of trap arrays operated across all trapping events where that species was collected (trials) at a site. The ratio of successes to trials gives an estimate of the average probability that the species will be caught in a trap array in one trapping event, given that the species is active. A 95\% confidence interval estimate for this proportion was obtained using the Wilson interval estimator, which provides robust estimates for proportions of small samples and values near zero or one (Agresti \& Coull 1998). These intervals were used to calculate the number of trap array events needed to detect the species for a range of detection probability values using the geometric distribution. Results for species that were collected only once at a site were not included because they gave estimates of sampling effort that were too imprecise to be informative.

Species accumulation curves were plotted to assess the completeness of the species inventory at each site. Rarefaction with 1000 iterations per sample size was used to produce smooth curves (Gotelli \& Colwell 2001). Curves were not produced for sites that were not sampled for an entire summer season, or for Boekenhoutskloof where only two trapdoor spider species were collected despite a sampling effort similar to other sites. The habitat at this site is a seasonally inundated bottom-slope with a shallow hard plinthic soil horizon. The periodic inundation that results from the shallow plinthic layer likely accounts for the low number of species collected there.

Active searching was also undertaken at the sampling sites at Onderstepoort Nature Reserve, Zwartkoppies, Luipaardsvlei and Faerie Glen Nature Reserve. The primary purpose was to obtain females of the species collected during pitfall trapping at these sites. Soil scraping was employed to locate burrows. Experience showed that soil scraping was superior to brushing the surface or scanning the soil surface by eye. Combined effort was not standardized and varied between the sites from approximately $12 \mathrm{~h}$ at Luipaardsvlei to over $30 \mathrm{~h}$ at Faerie Glen Nature Reserve and Zwartkoppies, and took place at different times of year. Only a subjective comparison of the two methods is possible, and the results are discussed accordingly. All mygalomorph families were included in the comparison.

A map of the study area showing sampling localities was prepared with ArcGIS Version 9.3 (Fig. 1). All analyses were 


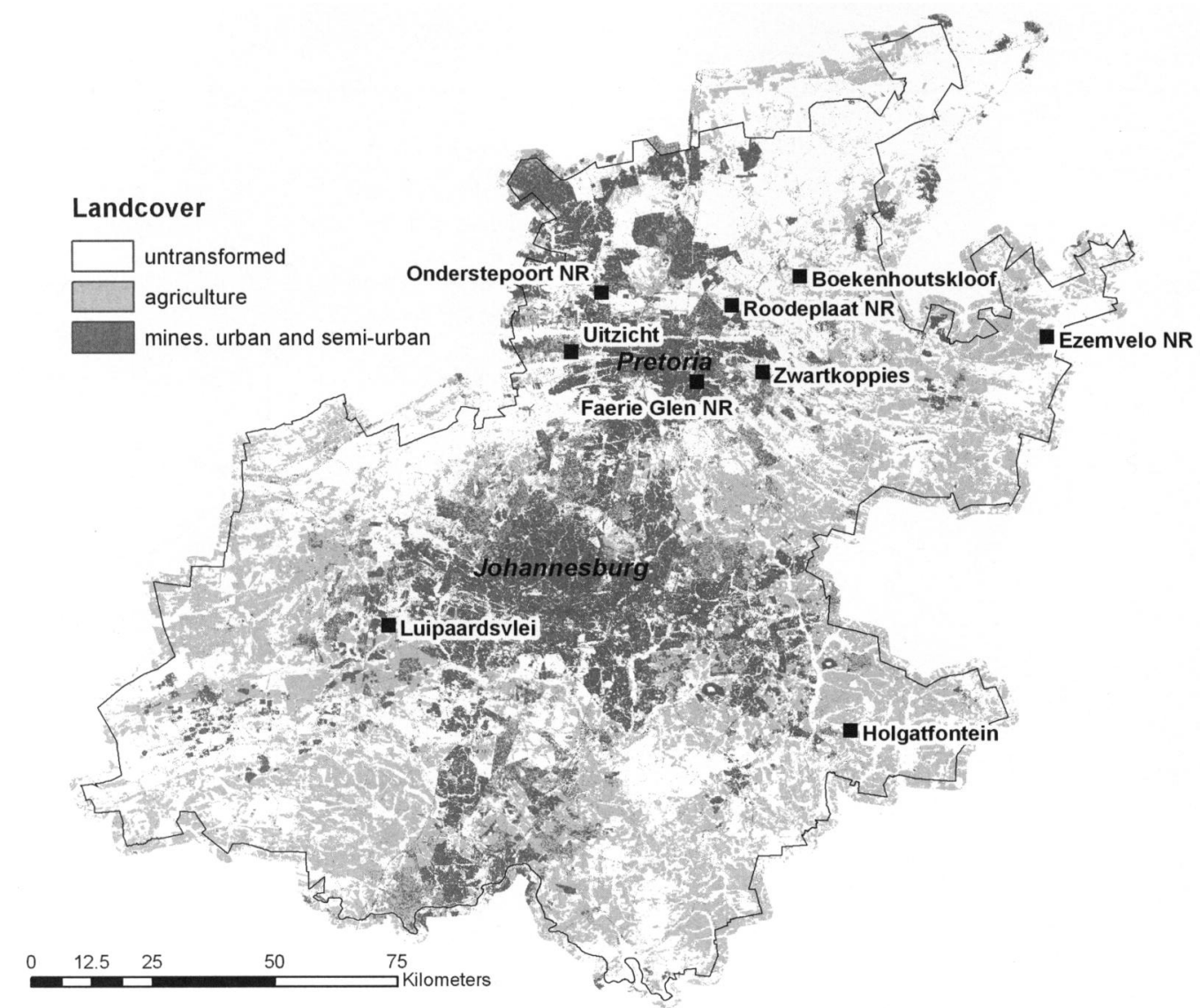

Figure 1.-Map of pitfall trap surveys localities for trapdoor spiders in Gauteng Province, South Africa, showing major urban and agricultural transformation. Landcover derived from GeoTerraImage (2009).

conducted with R Version 2.14.1 (R Development Core Team 2011).

\section{RESULTS AND DISCUSSION}

Phenology and environmental conditions.-A total of 220 trapdoor spider specimens, comprising eight species, were collected during the survey at Roodeplaat Dam Nature Reserve. 180 of these were marked and released, but none were recaptured. Stasimopus hewitti Engelbrecht \& Prendini 2012 was the most abundant species with 135 specimens collected, followed by Ancylotrypa brevipalpis (Hewitt 1916) with 53 specimens. Ancylotrypa rufescens (Hewitt 1916), Galeosoma hirsutum Hewitt 1916, Gorgyrella schreineri minor (Hewitt 1916) and Idiops pretoriae (Pocock 1898) were the rarest species at the site, with two to four specimens collected for each species. Ancylotrypa pretoriae (Hewitt 1913) and Segregara transvaalensis (Hewitt 1913) were more abundant, with 10 and 11 specimens collected respectively. In addition, the theraphosid species Brachionopus pretoriae Purcell 1904 was also collected in the pitfall traps, but only females were trapped. Another theraphosid, Augacephalus junodi (Simon 1904), was observed at the site but was never trapped.

Males of Ancylotrypa brevipalpis, Galeosoma hirsutum and Idiops pretoriae were active during October and November (Fig. 2). Galeosoma hirsutum and I. pretoriae had a relatively short activity period of two to three weeks, while $A$. brevipalpis was active for almost two months. Stasimopus hewitti was active for almost three months over the midsummer period of November to February, and Gorgyrella schreineri minor was active over three weeks in January. Ancylotrypa pretoriae was active from midsummer to early autumn (January to March), A. rufescens in late autumn (May) and Segregara transvaalensis in autumn (March to May).

Ancylotrypa brevipalpis and Stasimopus hewitti both showed a bell-shaped change in abundance through their activity period, with more specimens trapped in the middle of the activity period. A significantly larger than average number of specimens of each of these species was collected on a single occasion. For $S$. hewitti this occurred in early January, at approximately the middle of the activity period, with 50 specimens trapped, while for $A$. brevipalpis it occurred in early December, toward the end of the activity period, with 23 specimens trapped. The trimmed mean number of specimens trapped per day for each species was six for $S$. hewitti and three for $A$. brevipalpis.

Logistic regression of activity against environmental conditions identified no significant predictors of activity for any of the species analyzed individually, but showed soil moisture to be a significant predictor of activity when all species were analyzed together $(P=0.004)$. Plots of activity and rainfall show that male activity tended to occur within rainy periods (Fig. 2). It was also clearly apparent while doing the fieldwork that male trapdoor spiders would only be collected for a few days following significant rainfall events when the soil was 


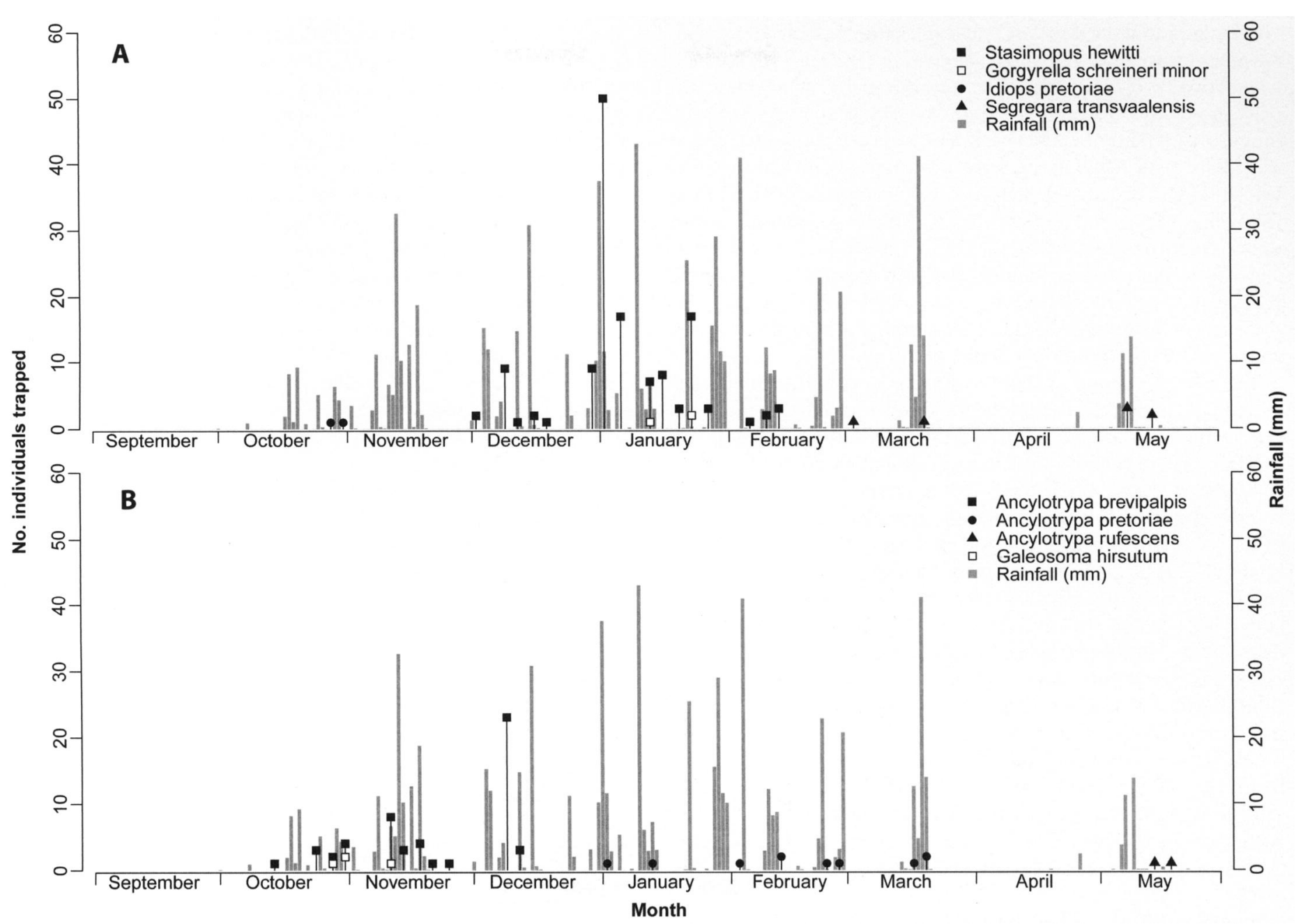

Figure 2.-Spike plots showing phenology of adult male trapdoor spiders, measured as number of individuals captured, at Roodeplaat Dam Nature Reserve, Gauteng Province, South Africa, as assessed during a pitfall trapping survey from September 2008 to May 2009.

visibly wet and there was significant dew formation. Plots of the raw data showed that activity was more common when humidity was high and when wind speed and evaporative demand were low. However, no activity also occurred under the same conditions, suggesting that measured environmental variables interact in a complex manner to influence surface activity in male trapdoor spiders. Low sample sizes, such as those obtained in this study, and which are likely to be characteristic of studies of mygalomorph spiders, are a limitation to identifying the nature of such complex relationships.

Subsequent sampling at other sites in the province confirmed the discrete periodicity of male activity and its dependence on the wet weather conditions observed at Roodeplaat. There appears to be some degree of seasonallybased correlation in activity between different species so that particular subsets of the total species assemblage are active at different times of the year. Broadly speaking these activity periods are October to November (early summer), November to February (mid-summer), February to April (autumn), and April to June (winter). Species active in the early summer period tend to have short activity periods of a few weeks.
Those that are active in mid-summer and autumn are active for longer periods. The observation of activity by some species in the winter months is unusual for mygalomorphs. An Ancylotrypa species was collected after two rainfall events in late May and mid-June at Boekenhoutskloof, and photographic evidence of male Stasimopus robertsi Hewitt 1910 active in June at Faerie Glen Nature Reserve, also following rainfall, was provided to the author by a member of the public. Due the rarity of winter rainfall events during the study period the data were insufficient to make general conclusions about winter activity patterns. In general, more species were active in the early summer and autumn periods than in mid-summer or winter. Activity peaked toward the end of April in the autumn period. Within the different families most idiopid species were active in the early summer and autumn periods, Stasimopus were never recorded in early summer, and cyrtaucheniids were active in all periods.

The general patterns in periodicity of activity described above were not without exceptions. Some species were found to be active at different times of the year at different localities. An example is Segregara transvaalensis, which was active from March to May at most localities, but was active in October and 
November at Onderstepoort and a site sampled near Hekpoort. Another example is Ancylotrypa nigriceps (Purcell 1902), which was active from midsummer to autumn at most localities but was only active for a short period in spring at Zwartkoppies. Single or small numbers of specimens were occasionally trapped outside of their usual activity periods. Segregara transvaalensis was collected in early September at Roodeplaat in the spring following the initial survey there. Single specimens of an undescribed Stasimopus Simon 1892 species and S. transvaalensis were collected in August at Zwartkoppies, and a single specimen of an undescribed Segregara Tucker 1917 species was collected at Luipaardsvlei in early summer where that species was found to be commonly active in autumn.

These surveys suggest that moisture is important for activity in atypids, ctenizids, cyrtaucheniids and idiopids, which were generally only collected under wet conditions following rainfall. Theraphosids and nemesiids appeared to be more tolerant of drier conditions. The emergences of adult male trapdoor spiders following rainfall have also been observed in other parts of South Africa and in East Africa (Neethling \& Haddad 2011; J. Leeming pers. comm.; P. Hawkes pers. comm.; I. Englebrecht pers. observ.). Some species that are active later in the season may also delay activity until several days after rainfall. Stasimopus robertsi males at Faerie Glen Nature Reserve only started wandering four days following a rainfall event in late April. The soil was still damp, and other trapdoor spider species were still active at the same time. The photographic record of this species provided to the author from the same locality was also taken several days after rainfall in June the year before. These observations, together with those of Coyle (1971), Coyle \& Icenogle (1994) and Main (1957), suggest a general pattern of rainfall-related activity for several mygalomorph families.

Sampling effort.- The average sampling effort required for a high probability of detecting all species present and active at a site ranged from two to seven nights of trapping using 10 trap arrays (Table 2). This seems to be a reasonable estimate for optimal sampling effort, given the experience gained during the study. Importantly, this must be interpreted as the sampling effort needed under suitable environmental conditions for spider activity and must be repeated at appropriate intervals throughout the year in order to obtain an inventory of the species present at a site. The large upper estimates of effort needed for some species indicated in Table 2 should be interpreted conservatively. These arise because the Wilson estimator produces less precise estimates for capture probability when the proportion of trials to successes is low (Agresti \& Coull 1998).

The species accumulation curves for Roodeplaat, Onderstepoort and Zwartkoppies are asymptotic, suggesting complete or near complete inventories for these sites, while those for Uitzicht, Faerie Glen and Luipaardsvlei are more linear (Fig 3). Rather than indicating incomplete inventories, the curves for Uitzicht, Faerie Glen and Luipaardsvlei result from a change in the sampling strategy employed. These sites were sampled about half as often as the others, with half the number of traps. Knowledge gained from the the earlier surveys was used to determine the timing and frequency of sampling needed to detect all species present with minimal sampling effort. An ideal sampling strategy with this objective should produce a linear species accumulation curve up to the total number of species present at the site. Departures from linearity would indicate sampling inefficiency. Such linear accumulation curves are not useful for evaluating inventory completeness, but given that the numbers of species collected was comparable to those obtained at other sites, the inventories are also likely to be complete or near complete.

The values in Table 2 and Fig. 3 can be used in planning future pitfall trapping surveys for trapdoor spiders by determining how much sampling effort is required for a certain pre-specified probability of detecting the species present, or for interpreting the results of surveys where sampling effort was limited by resource constraints (McArdle 1990). Planning should make provision for failed trapping events, such as when traps are flooded by heavy rainfall or when rainfall is insufficient to trigger spider activity. Studies should be planned according to clearly defined objectives, which can in turn be used to specify sampling effort. Yoccoz et al. (2001), MacKenzie \& Royle (2005) and Guillera-Arroita et al. (2010) provide guidelines for planning surveys with specific consideration of detection probability. In general, studies which aim to determine the presence of a single species at a single site, such as an EIA aiming to determine if a threatened species is present at a potential development site, should aim for the highest detection probability possible given the available resources. Occupancy studies, which aim to determine the proportion of sites where a species occurs, or studies that investigate species-environment relationships, can still provide valid results with lower detection probabilities as long as the appropriate statistical models are used to analyze the results (MacKenzie et al. 2002).

In comparing the relative efficacy of pitfall trapping and active searching, pitfall trapping yielded more species than active searching in all cases. At Zwartkoppies, pitfall trapping yielded seven species. Active searching failed to locate one of these and yielded only a single subadult specimen of another. At Onderstepoort pitfall trapping yielded six species and active searching yielded three, and at Luipaardsvlei pitfall trapping yielded six species while active searching yielded two. At Faerie Glen Nature Reserve pitfall trapping yielded eight species, while active searching yielded four. Total pitfall trapping yielded 1.2-3 times the number of species obtained by active searching at sites where both methods were employed. Active searching did not yield species that were not also caught in pitfall traps at any of the sites where both methods were employed. These results indicate that short-term active sampling efforts are unlikely to produce a complete inventory of a trapdoor spider species assemblage.

As expected both methods resulted in highly sexually biased samples, with active searching yielding primarily adult females and juveniles while pitfall trapping predominantly yielded adult males. Active searching was also more effective in habitats with harder, more clayey soils than in habitats with softer, sandier soils. This was probably due to the stronger soil structure of clayey soils, where burrows were less likely to collapse when the surface soil layer was removed. Dense vegetation covering the soil surface also made active searching more difficult, as burrows were presumably covered or collapsed in the process of removing the vegetation. Both methods also have their drawbacks. Active searching is labor 
Table 2.-Estimated detection probabilities and sampling effort for selected trapdoor spider species in Gauteng Province, South Africa. $\mathrm{x}$ : Number of successes, i.e., specimens collected in a trap array. x: number of captures, $\mathrm{n}$ : Number of trials, i.e., total number of trap arrays operated for trapping events when the species was?collected.

\begin{tabular}{|c|c|c|c|c|c|}
\hline Family/Species & Locality & $\mathrm{x}$ & $\mathbf{n}$ & $\begin{array}{l}\text { Estimated capture } \\
\text { probability per trap } \\
\text { array event. }\end{array}$ & $\begin{array}{l}\text { Number of trap arrays } \\
\text { required for } 90 \% \\
\text { detection probability. }\end{array}$ \\
\hline Atypidae Calommata transvaalica & Zwartkoppies & 9 & 60 & $0.081-0.261$ & $8-28$ \\
\hline \multirow[t]{3}{*}{ Ctenzidae Stasimopus hewitti } & Roodeplaat & 56 & 256 & $0.173-0.273$ & $8-13$ \\
\hline & Faerie Glen NR & 10 & 38 & $0.150-0.420$ & $5-15$ \\
\hline & Uitzicht & 3 & 20 & $0.052-0.360$ & $6-43$ \\
\hline Stasimopus sp. 1 & Holgatfontein & 2 & 18 & $0.031-0.328$ & $6-74$ \\
\hline Stasimopus sp. 2 & Luipaardsvlei & 6 & 10 & $0.313-0.832$ & $2-7$ \\
\hline Stasimopus sp. 3 & Onderstepoort NR & 9 & 58 & $0.084-0.269$ & $8-27$ \\
\hline Stasimopus sp. 4 & Zwartkoppies & 2 & 20 & $0.028-0.301$ & $7-82$ \\
\hline \multirow{2}{*}{$\begin{array}{l}\text { Cyrtaucheniidae Ancylotrypa } \\
\text { brevipalpis }\end{array}$} & Roodeplaat & 28 & 176 & $0.112-0.220$ & $10-20$ \\
\hline & Luipaardsvlei & 8 & 8 & $0.676-1.000$ & $1-3$ \\
\hline \multirow[t]{3}{*}{ Ancylotrypa nigriceps } & Holgatfontein & 3 & 18 & $0.058-0.392$ & $5-39$ \\
\hline & Luipaardsvlei & 2 & 10 & $0.057-0.510$ & 4-40 \\
\hline & Zwartkoppies & 5 & 70 & $0.031-0.157$ & $14-74$ \\
\hline \multirow[t]{4}{*}{ Ancylotrypa pretoriae } & Onderstepoort NR & 15 & 54 & $0.176-0.409$ & $5-12$ \\
\hline & Roodeplaat & 11 & 160 & $0.039-0.119$ & $19-59$ \\
\hline & Faerie Glen NR & 15 & 20 & $0.531-0.888$ & $2-4$ \\
\hline & Zwartkoppies & 5 & 20 & $0.112-0.469$ & $4-20$ \\
\hline \multirow[t]{3}{*}{ Ancylotrypa rufescens } & Boekenhoutskloof & 5 & 40 & $0.055-0.261$ & $8-42$ \\
\hline & Ezemvelo NR (Lookout) & 11 & 20 & $0.342-0.742$ & $2-6$ \\
\hline & Ezemvelo NR (red sand) & 13 & 20 & $0.433-0.819$ & $2-5$ \\
\hline \multirow[t]{2}{*}{ Idiopidae Galeosoma hirsutum } & Roodeplaat & 3 & 48 & $0.022-0.168$ & $13-107$ \\
\hline & Zwartkoppies & 23 & 100 & $0.158-0.322$ & $6-14$ \\
\hline \multirow[t]{3}{*}{ Galeosoma robertsi } & Faerie Glen NR & 4 & 8 & $0.215-0.785$ & $2-10$ \\
\hline & Onderstepoort NR & 36 & 50 & $0.583-0.825$ & $2-3$ \\
\hline & Uitzicht & 10 & 40 & $0.142-0.402$ & $5-16$ \\
\hline \multirow[t]{2}{*}{ Gorgyrella schreineri minor } & Ezemvelo NR (Lookout) & 4 & 10 & $0.168-0.687$ & $2-13$ \\
\hline & Roodeplaat & 2 & 32 & $0.017-0.202$ & $11-132$ \\
\hline Idiops fryi & Ezemvelo NR (Lookout) & 3 & 10 & $0.108-0.603$ & $3-21$ \\
\hline Idiops nigropilosus & Holgatfontein & 11 & 25 & $0.267-0.629$ & $3-8$ \\
\hline \multirow[t]{3}{*}{ Idiops pretoriae } & Roodeplaat & 2 & 32 & $0.017-0.202$ & $11-132$ \\
\hline & Faerie Glen NR & 3 & 8 & $0.137-0.694$ & $2-16$ \\
\hline & Zwartkoppies & 20 & 100 & $0.133-0.289$ & $7-17$ \\
\hline Idiops sp. & Luipaardsvlei & 5 & 10 & $0.237-0.763$ & $2-9$ \\
\hline Segregara sp. & Luipaardsvlei & 7 & 18 & $0.203-0.614$ & $3-11$ \\
\hline \multirow[t]{6}{*}{ Segregara transvaalensis } & Roodeplaat & 10 & 80 & $0.069-0.215$ & $10-33$ \\
\hline & Ezemvelo NR (Lookout) & 8 & 10 & $0.490-0.943$ & $1-4$ \\
\hline & Ezemvelo NR (red sand) & 14 & 20 & $0.481-0.855$ & $2-4$ \\
\hline & Faerie Glen NR & 3 & 20 & $0.052-0.360$ & $6-43$ \\
\hline & Onderstepoort NR & 11 & 50 & $0.126-0.352$ & $6-17$ \\
\hline & Uitzicht & 2 & 10 & $0.057-0.510$ & $4-40$ \\
\hline
\end{tabular}

intensive and often yields small numbers of specimens, which can be frustrating for the collector. Pitfall traps can get flooded by rain or damaged by animals. Where preservative is used, large quantities of unwanted by-catch, including small vertebrates, are killed and the preservative, which is usually toxic, may pose a threat to curious wildlife and livestock. The pitfall trapping method used for the surveys conducted in this study, while still labor intensive, was found to be preferable to active searching as it produced larger numbers of specimens and more species, and it avoided the problems associated with trapping using preservatives. Adult male spiders are also more useful for taxonomic and identification purposes than females, which further supports the use of pitfall trapping as the primary sampling method in trapdoor spider surveys. Although a more rigorous comparison of the relative efficacy of these two methods is needed, pitfall trapping appears to be the better option if time and resources are available.

Based on the results of the surveys described in this article the following principles should guide future surveys of trapdoor spider communities. Pitfall trapping is more effective than active searching when employed throughout the period of the year that adult male trapdoor spiders are active. Pitfall trapping should be used preferentially where long-term surveys are possible. Two to seven nights of trapping with ten trap arrays installed will give a high probability of detecting all species present and active at the time of trapping. To obtain complete or near complete species inventories, these sampling events should be repeated at regular intervals throughout the year, including the winter months, as different species are active at different times of the year. As several 

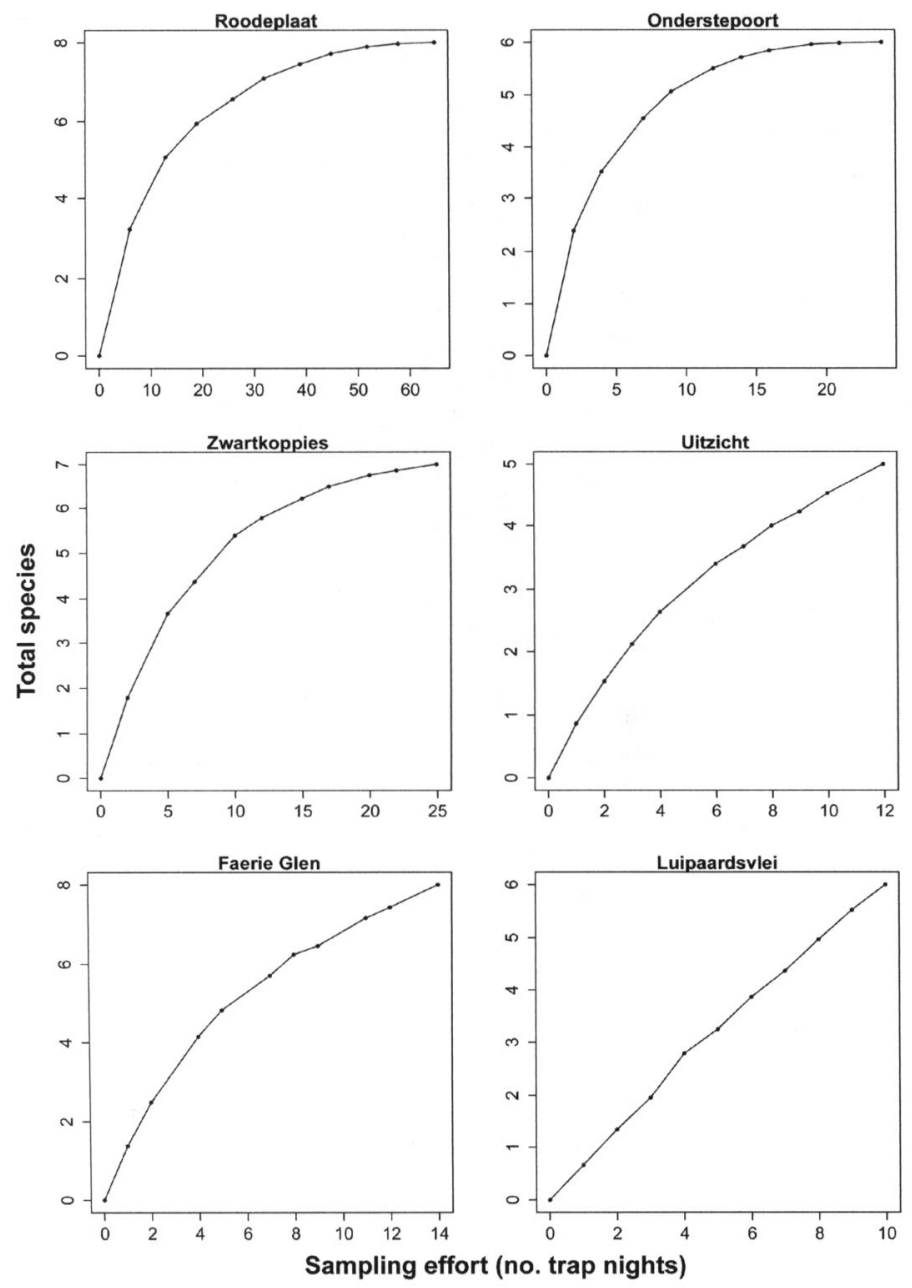

Figure 3.- Species accumulation curves for six localities surveyed for trapdoor spiders in Gauteng Province. Curves were produced by rarefaction with 1000 iterations per sample size. See text for discussion of inventory completeness.

species show relatively short activity periods of less than a month, sampling should take place approximately every two to three weeks, depending on suitable conditions. Sampling in early summer (mid-October to early November) and in autumn (late April and early May) are especially important, as more species are active during these periods than at other times of the year. Sampling should take place following rainfall events, as most trapdoor spider species are active under wet conditions, and should continue for several days so that species that delay their activity following rainfall are also detected. Sampling under dry conditions is generally unsuccessful for trapdoor spiders.

This study has provided guidelines for future surveys of trapdoor spiders in Gauteng Province. Resolving the current inadequacies in trapdoor spider systematics (Engelbrecht \& Prendini 2011), and ultimately gathering the data needed for conservation assessments, will require a substantial amount of survey work in the future. This should take place in a planned and structured way using the principles described above so as to maximize the return on the resources invested in surveys. Further research on the surface activity of male trapdoor spiders should include more detailed studies of weather-related activity that specifically aims to test the hypothesis that rainfall or moisture is the principal driver. Maximizing sample size should be a primary goal in such studies. Data analysis should consider interactions between variables and alternative methods of controlling for seasonal variation in abundance in order to make maximal use of raw count data. Before commencing major survey efforts researchers should invest in an effort to determine the times of the year that trapdoor spiders are active, particularly where climatic conditions differ from those in Gauteng Province. Finally, more accurate estimates of species-detection probabilities will be critical for planning surveys and analyzing survey results.

\section{ACKNOWLEDGMENTS}

Funds for pitfall trapping equipment were provided by the Diamond Route and E. Oppenheimer \& Son, with the assistance of Duncan MacFadyen. Funds for subsistence and travel were provided by the Gauteng Department of Agriculture and Rural Development. Robin Lyle, Martin Kruger, Dawn Larsen, Sarah Gess and Janet Beccaloni provided access to the type specimens used for identifications. Fieldwork was conducted by Matimba Baloyi, Richard Koko, Mohaka Lephuthing, Derrick Majebele, Jakob Makola, Aaron Matabane, Josh Mathebula, Wilson Molaba, the late Job Motsamai, Andries Mputhi, and Sipho Ndlovu in conjunction with the author. Richard Koko and Andries Mputhi deserve special mention for their tireless energy and good humor in the field. Lorraine Mills assisted with plant identification at Roodeplaat. Sean West assisted with fieldwork logistics. Chris Kaempffer, Garry Paterson and Johan Malherbe provided weather data and parameter values for evaporative demand and soil moisture estimation. Mark Robertson, Stano Pekár, Peter Hawkes, Michelle Correia and an anonymous reviewer provided suggestions for improvement of the manuscript.

\section{LITERATURE CITED}

Agresti, A. \& B.A. Coull. 1998. Approximate is better than "exact" for interval estimation of binomial proportions. American Statistician 52:119-126.

Austin, R.H., B.F. Phillips \& D.J. Webb. 1976. A method for calculating moonlight illuminance at the earth's surface. Journal of Applied Ecology 13:741-748.

Bond, J.E., D.A. Beamer, T. Lamb \& M. Hedin. 2006. Combining genetic and geospatial analysis to infer population extinction in mygalomorph spiders endemic to the Los Angeles region. Animal Conservation 9:145-157.

Bond, J.E. \& B.D. Opell. 2002. Phylogeny and taxonomy of the genera of south-western North American Euctenzinae trapdoor spiders and their relatives (Araneae: Mygalomorphae: Cyrtaucheniidae). Zoological Journal of the Linnean Society 136:487-534.

Briers, R.A., H.M. Cariss \& J.H. Gee. 2003. Flight activity of adult stoneflies in relation to weather. Ecological Entomology 28:31-40.

Clarke, G.M. \& F. Spier-Ashcroft. 2003. A Review of the Conservation Status of Selected Australian Non-marine Invertebrates. Environment Australia, Canberra.

Cooper, S.J.B., M.S. Harvey, K.M. Saint \& B.Y. Main. 2011. Deep phylogenetic structuring of populations of the trapdoor spider Moggridgea tingle (Migidae) from southwestern Australia: evidence for long-term refugia within refugia. Molecular Ecology 20:3219-3236. 
Coyle, F.A. 1971. Systematics and natural history of the mygalomorph spider genus Antrodiaetus and related genera (Araneae: Antrodiaetidae). Bulletin of the Museum of Comparative Zoology 141:269-402.

Coyle, F.A. \& W.R. Icenogle. 1994. Natural history of the Californian trapdoor spider genus Aliatypus (Araneae: Antrodiaetidae). Journal of Arachnology 22:225-255.

Cunningham, R.B. \& D.B. Lindenmayer. 2005. Modeling count data of rare species: some statistical issues. Ecology 86:1135-1142.

Curtis, D. 1980. Pitfalls in spider community studies (Arachnida, Araneae). Journal of Arachnology 8:271-280.

Dippenaar, S.H., A.S. Dippenaar-Schoeman, M.A. Modiba \& T.T. Khoza. 2008. A checklist of the spiders (Arachnida, Araneae) of the Polokwane Nature Reserve, Limpopo Province, South Africa. Koedoe 50:10-17.

Dippenaar-Schoeman, A.S. 2002. Baboon and Trapdoor Spiders of Southern Africa: An Identification Manual. Plant Protection Research Institute Handbook No. 13. Agricultural Research Council, Pretoria.

Dippenaar-Schoeman, A.S., M. van der Merwe \& A.M. van den Berg. 2006. Habitat preferences and seasonal activity of the Microstigmatidae from Ngome State Forest, South Africa (Arachnida: Araneae). Koedoe 49:85-89.

Edwards, D. 1983. A broad-scale structural classification of vegetation for practical purposes. Bothalia 14:705-712.

Engelbrecht, I. \& L. Prendini. 2011. Assessing the taxonomic resolution of southern African trapdoor spiders (Araneae: Ctenizidae; Cyrtaucheniidae; Idiopidae) and implications for their conservation. Biodiversity and Conservation 20:3101-3116.

Engelbrecht, I. \& L. Prendini. 2012. Cryptic diversity in South African trapdoor spiders: three new species of Stasimopus Simon, 1892 (Mygalomorphae, Ctenizidae), and redescription of Stasimopus robertsi Hewitt, 1910. American Museum Novitates 3732:1-42.

Foord, S.H., M.M. Mafadza, A.S. Dippenaar-Schoeman \& B.J. van Rensburg. 2008. Micro-scale heterogeneity of spiders (Arachnida: Araneae) in the Soutpansberg, South Africa: a comparative survey and inventory in representative habitats. African Zoology 43:156-174.

Gallon, R.C. 2002. Revision of the African genera Pterinochilus and Eucratoscelus (Araneae, Theraphosidae, Harpactirinae) with description of two new genera. Bulletin of the British Arachnological Society 12:201-232.

GeoTerralmage. 2009. 2009 Gauteng landcover dataset. Produced for the Dept. of Agriculture and Rural Development, Government of the Republic of South Africa. GeoTerraImage Pty Ltd., Pretoria.

Gotelli, N.J. \& R.K. Colwell. 2001. Quantifying biodiversity: procedures and pitfalls in the measurement and comparison of species richness. Ecology Letters 4:379-391.

Guillera-Arroita, G., M.S. Ridout \& B.J.T. Morgan. 2010. Design of occupancy studies with imperfect detection. Methods in Ecology and Evolution 1:131-139.

Høye, T.T. \& M.C. Forchhammer. 2008. The influence of weather conditions on the activity of high arctic arthropods inferred from long term observations. BMC Ecology 8:1-8.

Kéry, M. \& B.R. Schmidt. 2008. Imperfect detection and its consequences for monitoring for conservation. Community Ecology 9:207-216.

Lancia, R.A., J.D. Nichois \& K.H. Pollock. 1994. Estimation of number of animals in wildlife populations. Pp. 215-253. In Research and Management Techniques for Wildlife and Habitat. (T. Bookhout, ed.). The Wildlife Society, Bethesda, Maryland.

MacKenzie, D.I., J.D. Nichols, G.B. Lachman, S. Droege, J.A. Royle \& C.A. Langtimm. 2002. Estimating site occupancy rates when detection probabilities are less than one. Ecology 83:2248-2255.

MacKenzie, D.I., J.D. Nichols, N. Sutton, K. Kawanishi \& L. Bailey. 2005. Improving inferences in population studies of rare species that are detected imperfectly. Ecology 86:1101-1113.
MacKenzie, D.I. \& J.A. Royle. 2005. Designing occupancy studies: general advice and allocating survey effort. Journal of Applied Ecology 42:1105-1114.

Main, B.Y. 1957. Biology of aganippine trapdoor spiders (Mygalomorphae: Ctenizidae). Australian Journal of Zoology 5:402-473.

Margules, C.R. \& R.L. Pressey. 2000. Systematic conservation planning. Nature 405:243-253.

McArdle, B.H. 1990. When are rare species not there? Oikos 57:276-277.

McDonald, L.L. 2004. Sampling Rare Populations. Pp. 11-42. In Sampling Rare or Elusive Species: Concepts, Designs, and Techniques for Estimating Populations Parameters. (W.L. Thompson, ed.). Island Press, Washington.

Neethling, J.A. \& C.L. Haddad. 2011. Effect of lunar phases on the activity patterns of scorpions, solifugids and trapdoor spiders at the Free State National Botanical Gardens. Unpublished Honors Thesis, University of the Free State.

R Development Core Team. 2011. R: A language and environment for statistical computing. R Foundation for Statistical Computing, Vienna, Austria. Online at http://www.R-project.org/

Rodríguez-Iturbe, I. \& A. Porporato. 2004. Ecohydrology of watercontrolled ecosystems: soil moisture and plant dynamics. Cambridge University Press, Cambridge.

Russell-Smith, A. 2002. A comparison of the diversity and composition of ground-active spiders in Mkomazi Game Reserve, Tanzania and Etosha National Park, Namibia. Journal of Arachnology 30:383-388.

Scholes, R.J. \& B.H. Walker. 1993. An African Savanna: Synthesis of the Nylsvley Study. Cambridge University Press, Cambridge.

Schultz, R.E. 1997. South African Atlas of Agrohydrology and Climatology. Water Research Commission, Pretoria. Report TT82/96.

Southwood, T.R.E. \& P.A. Henderson. 2000. Ecological Methods. Blackwell Science, Oxford.

Thompson, W.L. (ed.). 2004. Sampling Rare or Elusive Species: Concepts, Designs and Techniques for Estimating Population Parameters. Island Press, Washington.

Uetz, G.W. \& J.D. Unzicker. 1976. Pitfall trapping in ecological studies of wandering spiders. Journal of Arachnology 3:101-111.

Valiantzas, J.D. 2006. Simplified versions for the Penman evaporation equation using routine weather data. Journal of Hydrology 331:690-702.

Van Dam, G. \& A. Roberts. 1917. Notes on nests of some trapdoor spiders and the nest of Calommata transvaalicus Hewitt. Annals of the Transvaal Museum 5:218-233.

Warui, C.M., M.H. Villet \& T.P. Young. 2004. Spiders (Araneae) from black cotton soils of a highland savanna in Laikipia, central Kenya. Journal of Afrotropical Zoology 1:13-24.

Whitmore, C., R. Slotow, T.E. Crouch \& A.S. Dippenaar-Schoeman. 2001. Checklist of spiders (Araneae) from a savanna ecosystem, Northern Province, South Africa: including a new family record. Durban Museum Novitates 26:10-19.

Whittaker, R.J., M.B. Araújo, P. Jepson, R.J. Ladle, J.E.M. Watson \& K.J. Willis. 2005. Conservation biogeography: assessment and prospect. Diversity and Distributions 11:3-23.

Williams, C.B. 1940. An analysis of four years of captures of insects in a light trap. Part II. The effect of weather conditions on insect activity; and the estimation of forecasting of changes in the insect population. Transactions of the Royal Entomological Society of London 90:227-306.

Wishart, G. 2006. Trapdoor spiders of the genus Migolas (Mygalomorphae: Idiopidae) in the Sydney Region, Australia, with notes on synonymies attributed to $M$. rappax. Records of the Australian Museum 58:1-18.

Wishart, G. 2011. Trapdoor spider of the genus Misgolas (Mygalomorphae: Idiopidae) in the Illawara and South Coast Regions of 
New South Wales, Australia. Records of the Australian Museum 63:33-51.

Woodcock, B.A. 2005. Pitfall trapping in ecological studies. Pp. 37-57. In Insect sampling in forest ecosystems. (S.R. Leather, ed.). Blackwell Publishing, Oxford.
Yoccoz, N.G., J.D. Nichols \& T. Boulinier. 2001. Monitoring of biological diversity in space and time. Trends in Ecology and Evolution 16:446-453.

Manuscript received 20 July 2012, revised 21 May 2013. 